Revista Iberoamericana. Vol. LXVI, Núm. 193, Octubre-Diciembre 2000, 771-784

\title{
COMPRENDER LA MODERNIDAD HETEROGÉNEA: RECOLOCAR LA CRÍTICA DENTRO DE LA CRÍTICA
}

POR

Hermann Herlinghaus

University of Pittsburgh

Las experiencias de una nueva "internacionalidad” del debate cultural han producido numerosas paradojas. Entre ellas se divisa la siguiente: tanto "Posmodernidad" como "Postcolonialismo" han apostado, aunque de manera diferente, por el potencial crítico de aquella metáfora que se llama "periferia". Al mismo tiempo, en la medida en que estos conceptos tendieron a convertirse en "macrodiscursos alternativos", han lucido nuevas prácticas de exclusión. Corrieron el riesgo de convertirse en lo que no debían ser. No debieran ser, en su identidad político-conceptual, sistemas explicativos al estilo de los grandes relatos. Sus potenciales críticos pueden volverse productivos de otra manera. Si bien hay profundas diferencias entre perspectivas posmodernas y postcoloniales, sus postulados éticos han sido íntimamente vinculados con la desintegración del lugar céntrico y conclusivo de la empresa intelectual moderna. Están conectados justamente por la búsqueda de estrategias nuevas de crítica de la modernidad en tiempos de la avanzada globalización. Y su fuerza no parecía residir solamente en una autorreflexividad radicalizada de sus propios contornos, antes bien hacía posible la asunción de la diversidad real del pensamiento crítico. Es sabido que la mera mención común de estos dos nombres puede producir escepticismo. Ambos fueron lanzados desde las academias de centro en contra de ideas y epistemologías establecidas, y en sus condiciones recanonizadoras del pensamiento de crisis de un discurso holístico de modernidad han llegado a afirmar territorios propios, valga decir distintos. Mientras tanto, en vista de los cambios en el mundo a partir de 1989 y de la creciente no unicidad de los repertorios de la crítica, se está disminuyendo la fascinación que ha acompañado el surgimiento de grandes conceptos alternativos. Esto es un rasgo del debate que también permite comprenderlos de otra manera. Pensamiento “posmoderno" por un lado, perspectivas "postcoloniales”, por el otro, incitan a que hoy se indague en la pregunta sobre si hay una fenomenología crítica conectora detrás de tramas intermitentes y una representatividad distanciadora de sus posturas. En los centros de la producción académica occidental, la reterritorialización global ha profundizado las divisiones de competencia entre esferas y agencias de la crítica que van, desde luego, todavía más allá de estas vertientes mencionadas. Pero desde ciertas perspectivas latinoamericanas no resulta sorprendente que un pensamiento crítico en torno a la modernidad articule horizontes e intereses cuyas habilidades dialógicas sean radicalmente transversales. 
En el mundo actual los pensamientos sobre la modernidad se han diseminado en diversas direcciones. Y es en las periferias de antaño como también en la Europa oriental, esto es, en lugares precarios de la producción de saberes normativos, donde las discusiones lucen una intensidad que todavía parece ir en aumento. Por debajo de lo diverso se esboza un cambio de sensibilidad vinculado a una "simetría" sorprendente, la que implica una profunda alteración de los criterios y horizontes de la investigación comparativa. Se trata de la simetría entre el desplome de los sistemas del socialismo estatal y una nueva dramaticidad en el estado de la modernidad capitalista: el desborde "no moderno" del hambre, de la crisis ecológica, del miedo. Las conocidas consignas que después de 1990 proclamaron el triunfo del liberalismo y de las democracias occidentales no han logrado tapar ni la desigualdad de las modernizaciones violentas de regiones periféricas ni una nueva conciencia crítica que, articulada desde estas regiones, cuestiona hoy la exclusiva competencia del mundo desarrollado sobre los asuntos de la modernidad. En lo que al debate crítico se refiere, la historicidad del pensamiento revela contornos paradójicos y al mismo tiempo recursos de diálogo que se tenían por desconocidos. A la luz de las dinámicas de modernización y globalización de los últimos quince años, el potencial de reflexión que fue introducido por el pensamiento posmoderno se ha quedado corto en vista de nuevas situaciones conceptuales. En cierto sentido, el histórico umbral de 1989/1990 ha sido a la vez la chance y el bloqueo de la posmodernidad, y no es casual que su eurocentrismo y algunas de sus euforias angloamericanas hayan entrado en crisis.

"Social theory fell into a total blackout when confronted with the changes in Eastern Europe. Social theory does not want to recognize that most of its notions do not have the same meaning as they had before" (Saleck 4). Este balance de Renata Salecl, teórica feminista de Slowenia, ya se había prefigurado en las ciencias sociales latinoamericanas de la década anterior, tiempo en que la "estratificación de los márgenes” dio entrada a una nueva especie de pensamiento “internacionalista”. Había escrito Nelly Richard: Hay que estar atento "hasta dónde esta glorificación postmodernista de lo descentrado llega a ser algo más que un subterfugio retórico, en circunstancias en que el centro —aunque se valga de la figura del estallido para metaforizar su más reciente descomposición— sigue funcionando como base de operaciones y puesto de control del discurso internacional” (La estratificación 58). Lo que insinuamos no es un grado, u otro lugar de descentramiento, sino realidades y constelaciones que han hecho "implotar" al universalismo de la modernidad: en el presente se divisa una envergadura de participación e interferencia epistemológica de las periferias que por primera vez, en el mundo entero, torna obsoleta cualquier exterioridad (conceptual y política) a lo moderno. El año 1990, año también de la publicación de Nation and Narration de Homi K. Bhabha, marca el momento del despliegue de un mapa distinto en términos de la historicidady “disemi-Nación” de lo moderno. Momento en que el postulado estratégico expresado por el colombiano-español Jesús Martín-Barbero y otros pensadores latinoamericanos —-(Itinerarios para) salir de la razón dualista (1989)— se encontró potenciado por nuevas exigencias de diálogo y proyectos críticos a nivel global. Por esto, mencionar juntos a Richard, Martín-Barbero, Salecl y Bhabha, significa cuestionar incluso "monopolios de descentramiento" que hasta hace poco parecían vinculados a determinados lugares hegemónicos. Se está hablando no simplemente de una diversificación de los 
territorios de la modernidad (y de la crítica), sino de otro profundo cambio en la historicidad de su episteme. Si se evoca la noción benjaminiana de la experiencia histórica, el verdadero estallido del historicismo como sistema paternalista de explicación se da con la entrada en la década del noventa del siglo veinte.

Una sensibilidad hacia estos cambios y hacia la historicidad concreta de los debates (que a veces son debates diversos bajo un mismo nombre) exige una perspectiva tan abierta como conceptualmente comprometida. Optamos por la noción modernidad heterogénea que se ofrece como un concepto de búsqueda cuyas bases y cuyos criterios forman parte de reflexiones que no encuentran ya presupuesto categorial seguro. Con este concepto se señala la necesidad de seguir buscando espacios y estrategias de descolonización epistemológica sin despedir la modernidad como horizonte. Sirve, en vez de reclamar un sistema categorial propio, para marcar diferencias y recolocar nexos de debate. El concepto, tal como lo esbozamos, señala un marco de historización doblemente diferencial, distinto tanto del discurso de una "posmodernidad legítima" como de algunas posiciones postcoloniales que ven todo pensamiento de modernidad preso en las lógicas de un discurso colonial. La episteme de la modernidad se constityue más por mecanismos de incorporación que de exclusión, o mejor dicho, de marginalización, subordinación y resemantización que funcionan por inclusión. De ahí el actual interés, "periférico” en gran medida, en la "hibridez" de la episteme de la modernidad. Situar hoy el problema de la diferencia cultural en el ámbito de inclusión, esto es, del funcionamiento concreto de la hegemonía y sus divergencias, implica llevar una atención no idealista hacia el discurso de la modernidad, a nuevos horizontes comparativos. Cabe repetir el gesto reformulador de un problema omnivalente: reconocer el problema de la diferencia cultural en su relación con las dinámicas y asimetrías de inclusión, hace aguda la tarea de historizar los nexos de modernidad y globalización con nuevos criterios comparativos. En los espacios de la ambivalencia se esconden los problemas más difíciles del análisis (de las mediaciones) de lo político. "Modernidad heterogénea" permite situar los problemas de "participación simbólica” y las asimetrías culturales, que caracterizan en cuanto mapas históricos de la modernidad occidental problemas políticos, en un marco de globalización cuyos cambios tectónicos reclaman hoy una radical apertura del debate. "Modernidad heterogénea” no es un concepto descriptivo sino un concepto que permite profundizar y reacentuar comparativamente el debate epistemológico.

Abogamos por una reflexión que relacione la "modernidad heterogénea” con la búsqueda de herramientas que permitan pensar los problemas de la cultura y, en grado mucho mayor que el acostumbrado, de comunicación, como problemas públicos que no tienen hoy resolución especulativa. Nuestra orientación reclama afinidad hacia aquellas perspectivas latinoamericanas que, bajo las designaciones de "modernidad nocontemporánea” (Martín-Barbero), "modernidad híbrida” (García Canclini), “modernidad periférica” (Sarlo, Brunner) han incidido de manera insólita en el debate entre humanidades y ciencias sociales. "Modernidad heterogénea” designa, sin embargo, un marco más extenso y diverso que el de las discusiones latinoamericanas. Confiere una perspectiva democráticamente abierta que permite historizar la modernidad a nivel mundial en vista crítica de las obsesiones centristas de varios “post”. En este sentido, el aporte de perspectivas 
latinoamericanas consiste en una radicalidad de apertura, "heterogeneidad radical” como dijera Cornejo-Polar (1996), que permite profundos virajes de enfoque. Entre ellos se dibuja aquel de un nuevo "materialismo hermenéutico" que nace de una mirada que sabe conectar insólitamente modernidad y comunicación. En ello se inscribe una reorientación de envergadura mayor: liberar la problemática de la comunicación de la tan perspicaz "razón dualista” (Martín-Barbero 1989) y reacentuarla a través de nexos conceptuales que resultan igualmente relevantes para las ciencias sociales, las humanidades, e incluso — como lo atestigua el "cultural turn" de los estudios de las ciencias en el mundo angloamericanolas ciencias naturales. Desde un pensamiento latinoamericano que se empeñó en problematizar la modernidad desde la comunicación y el descentramiento hermenéutico han surgido conceptos y potenciales de crítica epistemológica que todavía no tienen lugar de teoría.

En sus posturas se teoriza la alteridad a través de unos registros que a primera vista resultan algo consternantes. Se reflexiona sobre una modernidad que se ha convertido de un discurso de identidad (deseada) en un conjunto de discursos sobre la diferencia que marcan una respectiva precariedad en cuanto al alcance de un estado o un imaginario cuyos rasgos se han vuelto difusos. De la modernidad no hay escape, pero su sentido se hace fugaz. Las diferencias se manifiestan, por ejemplo, en logísticas de cercanía e interacción de paradigmas (su hibridación conceptual) que antes marcaban polos opuestos o distantes. Las preguntas se cruzan, y en los cruces queda por reformular un potencial divergente: ¿cómo pueden las "periferias" hoy reclamar e institucionalizar posiciones de enunciación filosóficas y epistemológicas en torno a categorías estratégicas de cultura y sociedad? ¿Hasta qué consecuencias llega la autorreflexividad en los “centros”? ¿Cómo organizar y concebir el diálogo entre diversas experiencias e intereses de descentramiento? Si los problemas de poder y democracia atraviesan los mismos debates culturales, ¿qué significa esto para la autorreflexividad de una crítica cuyo estatus académico depende de su capacidad hegemonizadora? Las interferencias desiguales en los debates que hoy se efectuan desde lugares periféricos no autonomizan los problemas, sino implican su reacentuación. ¿Tiene el pensamiento periférico como único camino de inclusión viable una reterritorialización alternativa en las academias fuertes de los centros, o pueden desarrollarse políticas de teorización cultural que confieren a los escenarios, que hasta ahora han sido escenarios “de recepción” o campos tácticos de un pensar nómada, un papel mayor con respecto a la producción y difusión de conceptos críticos? Mientras que estas preguntas se mantienen abiertas, habría que reflexionar productivamente sobre aquel cambio que permite comprender la resemantización de categorías hegemónicas (la modernidad, en primer lugar) como práctica de experiencia “propia” de agencias periféricas. Cambio que consiste en habilidades y condiciones de convertir la situación de ser receptores de teoría en una constelación que torna el "uso" de nociones dominantes en prácticas de producción de conceptos de diferencia. Una mirada tal se entiende como radicalización hermenéutica en la medida que permite cuestionar la autoexplicatividad de numerosos esquemas de diferencia. Hay un rasgo significativo en una parte de las reflexiones latinoamericanas: en la medida en que se reconoce el anhelo truncado hacia un discurso propio como reflejo de la dominación discursiva, tal como opera desde los centros, se cuestiona un deseo mimético (o contramimético), y se llega a horizontes epistemológicos menos dependientes. Ahora, la creciente “independencia” epistemológica de las periferias no las absuelve de una situación precaria 
en términos de “explicación”, esto es, de las desventajes históricas y políticas en cuanto a la producción de posiciones discursivas fuertes. Por esto, es la comprensión entendida como proceso de relecturas (en vez de contradiscursos) la que señala una sensibilidad hermenéutica de lugares subalternos de la modernidad, sensibilidad cuya autoconciencia radical contribuye hoy a su específica fuerza en medio del combate epistemológico y cultural.

Con estas reconsideraciones de la alteridad, la "modernidad heterogénea” permite relativizar un cierto centrismo filosófico y agudizar una conciencia "retórica” e intercultural que hace pensable las condiciones del "Otro" en términos menos idealistas. Se desplaza la razón holística, no hacia sistemas de explicación otros, sino hacia sus (des)usos, la identidad hacia sus diversas prácticas narrativas lo cual permite reforzar a nivel analítico-interpretativo el peso del concepto de comprensión frente a la exclusividad de determinadas categorías de explicación. En suma, un acercamiento a la modernidad rearticulado de esta manera, permite concretar las preguntas por un "otro" desigualmente involucrado, no un "otro" en que se confunde la conciencia crítica con esencias alternativas limpiamente recortables. Lo que en este marco de consideraciones han articulado pensadores como Martín-Barbero, Richard, García Canclini, Cornejo-Polar, Ortiz y otros, son perspectivas interculturales en torno a la modernidad en las que el lugar de la crítica se tiende a refigurar, en palabras de Nelly Richard, en los “bordes académicos” y los “saberes cruzados” (Residuos y).

Hablar entonces de espacios de reflexion latinoamericanos no equivale a la pretensión de una nueva representatividad. Frente a las academias fuertes de Occidente, nos parece que los espacios en los que se radicaliza agudamente un pensamiento nómada en torno a la modernidad han sido espacios latinoamericanos. Esa afirmación debe volverse sobre su aporía inherente: se trata, en criterios tradicionales de latinoamericanicidad, de un pensamiento atípico que, sin embargo, adquiere su habilidad productiva como escenario ex-centris. Es de un notable interés político, dentro y fuera de América Latina, dialogar con pensadoras y pensadores que, a partir de la década de los ochenta y bajo denominaciones de búsqueda como "modernidad no-contemporánea" han reformulado los presupuestos del debate cultural. Sus proyectos político-académicos o educativos varían según necesidades y recursos. Cambian dentro de las propias dinámicas con que la modernización incide en procesos académicos y extra-académicos, tornando el pensamiento cultural instancia negociadora entre el desencanto y la cercanía histórico-crítica. Hay una observación a la cual nos toca dedicarnos aquí: por un lado, la apelación de los nuevos pensadores de modernidad a las experiencias inmediatas de diversos actores sociales y su rotundo escepticismo frente a renovadas posturas de melancolía que reclaman un sentido crítico autónomo para el trabajo intelectual, figuran entre sus rasgos distintivos. Por otro lado, se renueva el concepto hermenéutico de la “comprensión” lo que, a primera vista, parece confundir ciertas expectativas críticas. ¿De qué manera puede vincularse la reformulación de una perspectiva hermenéutica con una aguda revisión epistemológica de la modernidad desde la periferia?

En el marco dado, nos interesa dialogar con la propuesta de Jesús Martín-Barbero. En ella se pone en jaque uno de los más tenaces desencuentros en el discurso hegemónico de la modernidad —el desencuentro entre modernidad y comunicación. Fue desde unos "estudios latinoamericanos de la comunicación” que se produjeron descentramientos en dos direcciones: descentramiento de la Modernidad-mayúscula por un lado, y de aquella 
renombrada tradición que remite a la construcción de discursos de modernidad compensatoria o "contramodernidad" por el otro. Estos estudios nacen de la aguda autoconciencia de culturas doblemente desheredadas — por la modernidad y por la globalidad neoliberal. Sin embargo, es la comunicación, un campo múltiplemente estigmatizado como cómplice de las dominaciones, la que permite reubicarse en medio del “desastre”. A través de este campo numerosos teóricos reformulan la antigua tarea hermenéutica de la comprensión bajo otras premisas.

La distinción entre explicación y comprensión, si se la refiere a dos actitudes con las que se puede enfrentar un texto, hace recordar a Dilthey. Éste, hacia finales del siglo diecinueve, había referido la "explicación” a un modelo de inteligibilidad fuertemente influido por las ciencias naturales. La “comprensión”, en cambio, designaba una actitud fundamental de las ciencias humanas, afán complejamente interpretativo (psicológico en el caso de Dilthey) que buscaba conferirles a estas ciencias un estatus propio frente a los avances de las ciencias naturales y las escuelas positivistas. Más tarde, la lingüística jugaba un papel decisivo para debatirles a las ciencias naturales el principio de la "explicación”. En el contexto actual del debate latinoamericano ya no se trata, en primer lugar, de actitudes frente a los textos. Hay más bien afinidad hacia aquellos ámbitos de los estudios culturales que frente a la linguística y la semiótica estructuralistas han reforzado la necesidad de la comprensión de lo cultural y al mismo tiempo de un descentramiento del monopolio hermenéutico de los textos y obras canónicas. Ahora, la teorización latinoamericana que aquí nos interesa va todavía más allá. Descubre en las tensiones entre explicación y comprensión un mayor conflicto epistemológico de la modernidad y, sin compartir el dualismo entre ambos lados, reclama en particular el principio de la comprensión para insertarse productivamente en una asimetría - la asimetría entre la creciente independencia epistemológica de la periferia y el lugar precario de sus nuevas concepciones en términos de autoridad e institucionalidad discursivas. El hecho de que en América Latina los estudios de la comunicación asumieron un papel protagónico en este sentido, puede ser visto como un fenómeno sui generis en el debate internacional.

Hay que percatarse que lo que ahí se denomina “estudios de la comunicación” difiere notablemente de lo que se llama estudios de la información o “media studies” en otras partes del mundo. La comunicación aparece como problemática no tanto de transmisión o manipulación, o en otro registro de estéticas de la expresión audiovisual, sino afín al sentido que se le daba en una tradición del pensamiento retórico, tradición a la cual también Antonio Gramsci había remitido: esfera opaca de autoridades negociadas, de sentidos comunes en movimiento conflictivo y conciliador al mismo tiempo, campo en que se teatralizan derechos y experiencias a participar en la esfera de lo común luchando por las formas y espacios de esa participación. Por ende: esfera pública en donde lo público designa hechos que no tienen resolución especulativa. Los debates sobre el cambio del espacio público han sido intensos durante las últimas décadas, pero repetidas veces han pasado por alto un problema que ya fue indicado por la retórica: el papel constitutivo de unos "sentidos comunes en movimiento” para un concepto social de la cultura (Thompson). Esto quiere decir también que la hegemonía no tiene resolución especulativa. Y tampoco la historicidad de la "industria cultural" o de los respectivos medios masivos y de sus interacciones socioculturales tienen resolución especulativa. Estas hipótesis nos acercan a una noción de 
hermenéutica que descansa en una perspectiva transversal. La hermenéutica, si es enfocada como pensamiento intercultural, dispone de importantes raíces que la vinculan con tales premisas — raíces que durante el siglo diecinueve fueron sucesivamente marginalizadas con el desarrollo de la "hermenéutica legítima” en el linaje de Schleyermacher y Dilthey, esto es, en el proceso de constitución (universalista) de la hermenéutica textual (y “monocultural”).

Por ahí cabe descubrir y trabajar ese nexo revelador que se despliega entre unas revisiones de la modernidad y un nuevo, valga decir heterológico, interés en la comunicación. El problema de las identidades en América Latina pasa hoy por el campo de la comunicación, campo en que las contradicciones se dan en su mayor opacidad mientras se siguen combatiendo intensamente, y donde reina la imprevisibilidad epistemológica. No hay fin de la historia, y no hay fin de (la construcción de) identidades. Es el desplazamiento de la relación entre identidades y acontecer histórico lo que se hace tan difícil de pensar. De ahí provienen fuerzas motrices para la formulación de un desafío que permite recolocar toda una serie de presupuestos del debate cultural: el desafío hermenéutico de conectar el principio de la historicidad de la comprensión con las necesidades de interpretación que los desarrollos de la comunicación massmediática y de sus mediaciones culturales, psicológicas, socio-cotidianas plantean.

Si el mundo actual es un mundo electronizado y múltiplemente conectado ¿cómo se puede enfocar el problema de la comunicación desigual y asimétrica más allá del funcionalismo y la acumulación? Los retos que suponen disponer de un pensamiento hermenéutico radicalizado señalan precisamente en esa dirección, ya que forman parte de la agenda de los problemas que están dramáticamente abiertos. Hermenéutica, interculturalidad y diferencia adquieren nuevos vínculos a la luz de un debate globalmente sensibilizado. Interés por las fisuras y desajustes en las dinámicas globales que resisten la tentación de redefinir la empresa crítica desde unos residuos supuestamente no contaminados. Por cierto, una tentación tal puede crecer nuevamente. La globalización aparenta generalizar principios como los de eficacia y competencia sobre la base de saberes especializados, explicativos, altamente funcionalizados, que tienden a volver obsoletos los saberes críticamente interpretativos. Pero cabe percatarse de que entre las viejas lógicas (la modernidad dualista) y las nuevas logísticas (las reterritorializaciones funcionales que mercado y finanzas parecen instalar en cualquier lugar del mundo) se ha abierto un enorme déficit conceptual. Consiste en la ausencia de mayores esfuerzos que se plantean el reto de una arqueología y una hermenéutica de las dinámicas de la comunicación de un mundo complejamente globalizado.

La avanzada globalización ha reforzado las exigencias interpretativas que los estudios culturales enfrentan. No hay pensamiento crítico sin capacidad de interpretación, sin intentar comprender-explicar lo cultural como diversidad de narraciones y de discursos en movimiento, en conflicto, es decir sin capacidad de análisis retórico de la experiencia cultural y los imaginarios. La hipótesis del fin de los grandes relatos, que Lyotard una vez refirió a la legitimidad normativa de los metadiscursos “especulación”, “emancipación” y "revolución”, a menudo fue generalizada ingenuamente. Una notable parte de la crítica cultural, traumatizada por la difusión “ecológica” de poderes y la contaminación massmediática de los mundos de vida, suele manifestar un rechazo del estatus retórico y narrativo de lo cultural. Según un determinado esquematismo que acompaña estas posturas, 
se acuña la ecuación “narración-esencialismo”, “sentido común-autoridad”, olvidando el criterio gramsciano de que el pensamiento cultural no puede prescindir de los niveles y referentes de una "filosofía de la práctica”. Hay una laguna conceptual que ni el postestructuralismo ni la posmodernidad de los centros se empeñaron en profundizar: pensar una hermenéutica cultural y comunicacional que formula la necesidad de interpretación de las nuevas experiencias que se están viviendo desde diferentes estrategias y tácticas de participación, discursivas por un lado, narrativas por el otro, en los círculos de des- y reterritorialización simbólica del mundo de hoy. Para analizar los conflictos que pasan por estas zonas opacas, zonas de contacto y conflicto tremendamente brisantes, el pensamiento cultural latinoamericano ofrece estímulos interesantes.

El problema de la comprensión atraviesa hoy una variedad de preocupaciones científicas que se extiende desde la actualidad del pensamiento interpretativo de Nietzsche (Vattimo; Figl; Hoffmann) hasta la indagación hermenéutica en nuevas "ecologías del saber", por ejemplo en el contexto del agudo interés "literario-interpretativo" de las ciencias naturales y técnicas durante los últimos veinte años (ver entre numerosas referencias: Rosenberg; Piscitelli, Ciencia en; Latour; Luhmann; Hayles; Bono; Peterfreund). Tanto más asombroso luce una cierta marginalización de la hermenéutica en sus terrenos supuestamente más familiares —el filosófico-cultural y el de una notable parte de las discusiones en torno a la modernidad-, hecho que encontró un antecedente revelador en el desencuentro programático entre Derrida y Gadamer en París en 1983.

Recordemos que el nuevo pensamiento latinoamericano en torno a la modernidad que se viene articulando desde los años ochenta, encuentra un rasgo común en su toque radicalmente "antihistoricista", poniendo en jaque la idea de un "Macondo-América” la que, en la acepción de José Joaquín Brunner, acuñaba el sueño de un mundo vital latinoamericano que anhelaría salvarse de sucumbir ante la desencantadora modernización (Herlinghaus, Walter 20). Historicismo es entendido aquí, a diferencia de historicidad, como concepto lineal y finalista de lo histórico tal como Walter Benjamin lo había criticado: "historicismo" que, vaciado de las experiencias paradójicas de unos imaginarios actuantes, explicaba y objetivizaba el movimiento de lo histórico como efecto de las gravitaciones que supuestamente operan desde el centro de la modernidad (como sistema de órdenes discursivos) hacia sus bordes y sus antesalas. La crítica benjaminiana del historicismo ha encontrado en la América Latina de los decenios recientes su tal vez más audaz recepción (M.-B., Herlinghaus 2000), haciéndose parte de una “otra” perspectiva hermenéutica. Esa perspectiva apunta hacia una inusitada radicalización epistemológica del "sentido de la modernidad”.

Escribió Martín-Barbero en 1998: “[...] el tema de comunicación y modernidad nos concierne de un modo bien particular a los latinoamericanos, pues lo que en él se nos plantea no es tanto una cuestión de actualidad sino la del sentido mismo de la modernidad latinoamericana, o mejor la trama de modernidad y discontinuidades culturales, de anacronías y utopías que sostiene y resiste, asimila y enfrenta la comunicación en nuestros pueblos” (“Identidad comunicación” 83). El “sentido mismo”, en el contexto dado, no es nada menos que un término teleológico, y tampoco confiere calidad normativa. En vez se trata de un “concepto retórico”. Según este, la comprensión de la modernidad indica una diferencia frente al discurso explicativo, y se la busca —más allá de la “écriture”— en un 
saber común que reclama necesidad de análisis a través de conceptos como por ejemplo el concepto de "Meinen” [según la palabra gadameriana: “insinuar desde” un saber común que trasciende la autoridad de un enunciador individual al dar sentido a lo "no dicho" - lo insinuado]. ¿Cómo habla, al margen de las agencias explicatorias de la palabra convertida en orden de discurso, un “saber común”? No habla, como se le ha atribuido a menudo, desde esferas desestructurantes del lenguaje en donde el deseo (opaco y subconsciente) hacia el sentido equivale a su constante ruptura en los actos de significación. Esto es, no habla desde un "más allá" del discurso, sino desde un descentramiento del discurso: desde un nivel de otredad que sin embargo es articulación en las esferas del lenguaje. Marcamos aquí, en una línea de argumentación afín al pensamiento de Paul Ricoeur, una asimetría entre discurso y experiencia, discurso y deseo, discurso y memoria, discurso y muerte, haciendo hincapié en un concepto fenomenológico-cultural de la narración. Un "saber común” que (todavía o ya) no tiene palabra explícita u ordenadora, tiende a "hablar” desde la narración. Esta hipótesis dista de ser tipológica, su objetivo es más bien epistemológico en la medida que permite establecer una esfera de diferencia cultural que no comparte el dualismo entre lo discursivo y lo no discursivo, sino que permite preguntar por lógicas culturales vigentes en los márgenes del discurso. De ahí el propósito de repensar el concepto de la comprensión como concepto crítico dentro de la crítica. Nos interesa reflejar, para aplicar un término propuesto por Mario J. Valdés, sobre un horizonte "hermenéutico postestructuralista”, cuestionando la renovación del deseo hacia la purificación de la crítica. Se trata, si recordamos unos prolegómenos del contexto latinoamericano, de la crítica de un discurso holístico de la modernidad sin que se pueda constituir (esto es, sin los respectivos poderes institucionales y simbólicos) órdenes discursivos alternativos. En ese marco de crítica de la modernidad, la "narración”, tal como la entendemos a nivel epistemológico, no indica cumplimiento sino repetición, dilatación, desplazamiento: posibilidad de reapropiación y renarración de lo que se impone como orden de discurso. De ahí, un comprender conlleva a la suspensión de identidades estáticas a favor de identidades performativas, ya que "el sentido" tiende a "cumplirse" en el desplazamiento narrativo (y re-narrativo) que la participación en imaginarios colectivos en tanto imaginarios de acción implica.

Los mapas conceptuales de lo que llamamos "imaginarios de acción” requieren una exploración más detenida. Lo importante que queda por resumir aquí es el triple desplazamiento en tanto imaginario: de la contemplación a la acción, de los imaginarios individuales (supuestamente "puros") a unos imaginarios comunes (“contaminados”), de la producción (y distribución) del imaginario a su residualidad dinámica. No se trata de una rehabilitación cultural de los medios masivos, y la argumentación tampoco se limita a señalar la existencia de espacios “disfuncionales” en términos de la comunicación vista como práctica de poder. Se trata de pensar otro concepto de comunicación cuyas implicaciones van más allá de extraerles inteligibilidad a las ecologías mediáticas: ese concepto apunta hacia la comprensión de unas aporías claves de la modernidad. De ahí no sorprende que sea el pensamiento de identidad donde se reintroducen los “imaginarios de acción”: “[...] la cuestión de la identidad emerge hoy en el discurso de los comunicólogos latinoamericanos como síntoma de la crisis radical que atraviesan tanto el modelo de desarrollo como los paradigmas conceptuales que desde la derecha y la izquierda lo sostuvieron” (MartínBarbero, “Identidad, comunicación” 84). La crítica epistemológica de Martín-Barbero 
apunta en dos direcciones, y recién desde ahí se hace inteligible el nexo comunicaciónmodernidad. La necesidad de pensar más allá de los órdenes del discurso abarca esferas culturales distintas: la normatividad establecida desde las letras, y al mismo tiempo las promesas articuladas desde el progreso de una "sociedad informatizada”. Lo que, según el autor, "la experiencia de nuestros pueblos dominados pero culturalmente vivos pone hoy en cuestión”, es lo que acerca el mito de la "alienación universal” con respecto a la cultura de masas al mito de la emancipación universal letrada. Ambos viven de la "razón dualista". De ahí se hace necesario ubicar "la cuestión cultural” en otro ámbito de problemas.

\begin{abstract}
Residuo indigerible para unos y otros, la cuestión cultural se impone hoy como una clave insoslayable de acceso y comprensión de las dinámicas y los bloqueos, de los decepcionantes resultados que han dejado los "milagros" económicos o de lo mentiroso de las pasividades y las inercias atribuidas por los salvadores de turno a las colectividades. Es el mito mismo de la massmediación universal — gestado a partir de aquellas concepciones aparentemente antitéticas, pero secretamente conectadas al etnocentrismo, que identificaron la comunicación masiva con la decadencia cultural o la proyectaron como disolución final de las contradicciones o las diferencias - que la experiencia de nuestros pueblos dominados pero culturalmente vivos pone hoy en cuestión. Y no desde una ilusoria identidad salvada del naufragio, burlada al sistema o no tocada por el imperialismo sino desde las formas propias de simbolizar los conflictos, las luchas y los pactos, desde la opacidad de los mestizajes, la desposesión y las reapropiaciones. (Martín-Barbero, "Identidad, comunicación” 84)
\end{abstract}

Hemos esbozado contornos de un horizonte de comunicación que, al insertarse en marcos conocidos como aquel de la teatralidad del lenguaje y de los saberes, los reformula sin angustia de actualizar y desidealizar al mismo tiempo el interés por las matrices culturales "generadoras de comunidad". La pregunta por la historicidad hermenéutica de lo cultural - la pregunta "cuánto acontecer es operante en todo comprender" - ya fue formulada por Gadamer (25), quien ha ligado la noción del "círculo hermenéutico” de manera infeliz con el principio de una supuesta "fusión de horizontes" (no necesariamente “con” pero "a través” del otro) como base del comprender. No es de asombrar que Derrida haya reprochado a una visión tal del comprender una apropiación y un oscurecimiento del otro como figura de diferencias (130). Pero en la medida en que nociones como "círculo hermenéutico" y “fusión de horizontes”, las que desembocan en las reflexiones de Gadamer en un sorprendente conservadurismo epistemológico, se sometan a un radical cuestionamiento desde las mediaciones socio-culturales entre conocimiento y re-conocimiento (MartínBarbero, “Identidad, comunicación” 83), se hace superable un concepto idealista y logocéntrico de la comprensión.

El libro De los medios a las mediaciones de Martín-Barbero marca, para América Latina, un paso decisivo hacia una hermenéutica de la heterogeneidad sociocultural en tiempos de la avanzada globalización. Al mismo tiempo, en términos de un debate más extenso, el texto puede ser leído como historia conceptual de otra modernidad. A través de un esfuerzo desesencializador de los conceptos de cultura popular y espacio público que resultó hasta entonces desconocido, el autor logra actualizar la noción retórica de "sentido común”, tanto con fines de crítica epistemológica de la modernidad como con el objetivo 
de reformular el problema de identidad-“socialidad” en su estar atravesado por los desarrollos de la comunicación masiva. Ahí está, por ejemplo, la teoría de lo melodramático de Martín-Barbero como matriz intercultural de una modernidad heterogénea latinoamericana, la que hace comprender cómo por el "sentido común” pasan conflictos políticos en sus manifestaciones cotidianas, que fueron tantas veces subestimados por la filosofía y la filología modernas en sus variantes post-retóricas. Una premisa aparentemente simple alberga en su interior una serie de cuestiones que ayudan a acercarse a las aporías del presente. El “sentido común” marca aquella esfera en donde los mecanismos de reconocimiento suelen constantemente desplazar a los de conocimiento. Es la dimensión subjetiva que atraviesa "la socialidad” en los espacios más sensibles (y preferentemente estigmatizados por la crítica) del “pacto social” (ver Martín-Barbero y Muñoz 27).

De esta manera se logra, en términos de historización conceptual de la modernidad, reconectar desde la periferia la industria cultural/cultura de masas con las constituyentes sociohistóricas de comunidad. En otras palabras: la desconexión epistemológica de ambos lados remite no sólo a la "reducción [kantiana] del sentido común al gusto, sino también [a] la restricción del concepto mismo del gusto" a las bellas artes (Gadamer 76). Hay que ir más allá del balance de un Gadamer. El concepto del gusto no fue solamente restringido a las bellas artes sino convertido en herramienta del logo- y etnocentrismo de la modernidad centrada. La histórica edificación de un concepto del “mal gusto” sirvió como fundamento para negar o reducir toda una dimensión de alteridad dentro de lo cultural moderno, expulsión cuya mayor carga tenía que enfrentar el pensamiento periférico. Con la ayuda del prejuicio programático del “mal gusto” se desconectaba (la noción de) la moderna industria cultural de (los conceptos de) las constituyentes socio-simbólicas y cotidianas de comunidad. Y por debajo de "sociedad” se olvidaban no sólo a las “comunidades” sino al mismo tiempo se marginalizó (se deslegitimó) la heterogeneidad cultural como dinámica clave dentro de la modernidad y en sus bordes. Anota Martín-Barbero con respecto a la comprensión de una modernidad descentrada:

Necesitamos de un serio esfuerzo de descentramiento para romper con un pensamiento lineal y maniqueo como el que nos impide comprender la envergadura de una cultura que no sólo ha dejado de tener por eje al libro, sino que se alimenta, en el caso de América Latina, de la secreta complicidad entre la oralidad cultural de las mayorías y las narrativas de la visualidad electrónica. (“De la comunicación a la” 206)

Modernidad descentrada que plantea la necesidad de una alfabetización y politización cultural alternativas. Un tal concepto de modernidad contribuye a (re)dirigir la mirada hacia un más largo proceso que es doblemente discontinuo: con respecto al desarrollo de las grandes jerarquías culturales y epistemológicas, y en relación con las respectivas diferencias que se dan como indicios de historicidad de un mundo que es moderno por ser desigual.

Un materialismo hermenéutico, en la medida en que contribuye a minar "la razón" dualista, bien puede tener efectos liberadores. Puede designar un aporte significativo a lo que Rigoberto Lanz llama, en un estudio sobre subjetividad y poder, "un horizonte en el cual se inscribe una nueva sensibilidad, una nueva capacidad de compromiso, otra sociabilidad, una radicalmente distinta discursividad" (60-61). Sin embargo, recomenzar a hablar de 
"hermenéutica” hoy resulta empresa difícil. Exige en el comienzo un radical cuestionamiento de las pretensiones universalistas de la hermenéutica textual. Una parte del pensamiento latinoamericano en torno a la modernidad — modernidad heterogénea- ha abierto una pista apenas investigada. Muestra en vista de los escenarios de la globalización, los que también marcan nuevas jerarquías en el pensamiento crítico, que virar radicalmente la perspectiva hermenéutica permite retomar cuestiones de compromiso de una manera poco espectacular y sin embargo ambiciosa.

¿Para quiénes cobra particular y vital intensidad un manejo compartido de saberes de comprensión? Para todos aquellos que están marginalizados de la producción y numerosas veces de la circulación de las normas discursivas y los saberes explicativos de una sociedad, excluidos de esferas de poder a los que hoy en día pertenecen también las redes electrónicas y los nuevos códigos tecnoculturales como normas simbólicas (Piscitelli, Ciberculturas 226-237). En tales contextos de emergencia multiplicada, diversificada y sin embargo precaria de comunidades de actores alternativos, “saber comprender” significa literalmente vivir, mientras que para vivir en los dominios de producción y dominación hay que "saber explicar”. Es posible que la distinción sea más complicada, ya que no debe pensarse como dualismo. Recolocar la crítica dentro de la crítica requiere cierta modestia en términos de la representatividad del intelectual. Al mismo tiempo, la modestia deja de ser modestia cuando se trata de la defensa de un principio clave: la necesidad de comprender de otra manera, un comprender que al funcionar por descentramiento de los círculos instalados por los poderes cínicos, no deja de construir comunidad. Con esto no se refuta la necesidad formulada por perspectivas subalternas de reinventar las rupturas como medio de la acción política. La acción política no puede prescindir de la comprensión. Porque en términos hermenéuticos, la consecuencia de la ruptura sería la soledad. Dos urgentes tareas un tanto conflictivas entre sí —el compromiso social y la democratización de la crítica- precisan de una conciencia comprensiva de cómo actuan las subjetividades y de cómo los imaginarios se tornan rebeldes. A partir de ahí, el "comprender" ayuda a cuestionar la persistencia de la explicación cuando se torna fundamento de una "crítica representativa”. Pensamos que la crítica encuentra hoy otras tareas que la conservación de la pureza del discurso. De esto se está hablando cuando aquí se reflexiona sobre la tarea de recolocar la crítica dentro de la crítica.

BiBLIOGRAFÍA

Bhabha, Homi K. (ed.). Nation and Narration. Londres/Nueva York: Routledge, 1990.

Bono, James J. "Literature, Literary Theory, and the History of Science”. Publication of the Society for Literature and Science 2 (1986).

Cornejo-Polar, Antonio. "Una heterogeneidad no dialéctica. Sujeto y discurso migrantes en el Perú moderno”. Revista Iberoamericana LXII/176-177 (julio-diciembre 1996): 837-844.

Derrida, Jacques. “Guter Wille zur Macht” [Buena voluntad hacia el poder]. Text und Interpretation. Philippe Forget, ed. Muenchen: Wilhelm Fink Verlag, 1984.

Figl, Johann. Interpretation als philosophisches Prinzip. Berlin/Nueva York: Walter de Gruyter, 1982. 
Gadamer, Hans-Georg. Verdad y método I. [1960]. Salamanca: Ediciones Sígueme, 1997. Hayles, N. Katherine. "Literature and Science”. Encyclopedia of Literature and Criticism. M. Coyle et.al., eds. Detroit: Gale Research, 1991.

Herlinghaus, Hermann. Modernidad heterogénea. Descentramientos hermenéuticos desde la comunicación en América Latina. Caracas: Ediciones del CIPOST, 2000.

y Monika Walter, editores. Posmodernidad en la periferia. Enfoques latinoamericanos de la nueva teoría cultural. Berlin: Langer Verlag, 1994.

Hoffmann, Johann Nepomuk. Wahrheit, Perspektive, Interpretation. Nietzsche und die philosophische Hermeneutik. Berlin/Nueva York: Walter de Gruyter, 1994.

Lanz, Rigoberto. La deriva posmoderna del sujeto. Para una semiótica del poder. Caracas: Consejo de Desarrollo Científico y Humanístico-Universidad Central de Venezuela, 1998.

Latour, Bruno. Nous n'avons jamais été modernes. Essai d'anthropologie symétrique, Paris: Éditions La Découverte, 1991.

Luhmann, Niklas y Karl Eberhard Schorr. Zwischen Intransparenz und Verstehen. Frankfurt: Suhrkamp, 1986.

Martín-Barbero, Jesús. Procesos de comunicación y matrices de cultura. Itinerario para salir de la razón dualista. México DF: Gustavo Gili-FELAFACS, 1989.

De los medios a las mediaciones. Comunicación, cultura y hegemonía. Barcelona: Editorial Gustavo Gili, 1987.

y Hermann Herlinghaus. Contemporaneidad latinoamericana y análisis cultural. Conversaciones al encuentro de Walter Benjamin. Madrid/Frankfurt: IberoamericanaVervuert, 2000.

y Sonia Muñoz. Televisión y melodrama. Bogotá: Tercer Mundo Editores, 1992.

"De la comunicación a la filosofía y viceversa: Nuevos mapas, nuevos restos”. Mapas nocturnos. Diálogos con la obra de Jesús Martín-Barbero. María Cristina Laverde Toscano, Rossana Reguillo, eds. Bogotá: Universidad Central-Siglo del Hombre Editores, 1998.

“Identidad, comunicación y modernidad en América Latina”. Posmodernidad en la periferia. Enfoques latinoamericanos de la nueva teoría cultural [1989]. Hermann Herlinghaus y Monika Walter, eds. Berlin: Langer Verlag, 1994.

Peterfreund, Stuart (ed.). Literature and Science. Theory and Practice. Boston, 1990.

Piscitelli, Alejandro. Ciberculturas en la era de las máquinas inteligentes, Buenos Aires: Editorial Paidós, 1995.

Ciencia en movimiento. La construcción social de los hechos científicos. [1993]. I y II. Buenos Aires: Centro Editor de América Latina, 1994.

Richard, Nelly. Residuos y metáforas. Ensayos de crítica cultural sobre el Chile de la Transición. Santiago: Editorial Cuarto Propio, 1998.

La estratificación de los márgenes. Santiago: Francisco Zegers Editor, 1989.

Ricoeur, Paul. Temps et récit. Paris: Éditions du Seuil, 1985.

Rosenberg, Charles E. "Towards an Ecology of Knowledge”. The Organizations of Knowledge in Modern America. Alexandra Oleson, John Voss. Baltimore: Johns Hopkins University Press, 1979. 
Salecl, Renata. The Spoils of Freedom. Psychoanalysis and Feminismafter the Fall of Socialism. Londres/Nueva York: Routledge, 1995.

Thompson, E. P. Customs in Common. Londres: The Merlin Press, 1991.

Valdés, Mario J. (ed.). Reflection and Imagination. A Ricoeur Reader. Toronto/Buffalo: University of Toronto Press, 1991.

Vattimo, Gianni. El fin de la modernidad. Nihilismo y hermenéutica en la cultura posmoderna. Barcelona: Editorial Gedisa, 1987. 